\title{
Motivation for Heat Adaption: How Perception and Exposure Affect Individual Behaviors During Hot Weather in Knoxville, Tennessee
}

\author{
Alisa L. Hass ${ }^{1, *(1)}$ and Kelsey N. Ellis ${ }^{2}$ (D) \\ 1 Department of Geosciences, Middle Tennessee State University, Murfreesboro, TN 37132, USA \\ 2 Department of Geography, University of Tennessee, Knoxville, Knoxville, TN 37996, USA; ellis@utk.edu \\ * Correspondence: alisa.hass@mtsu.edu; Tel.: +1-615-898-2730
}

Received: 1 August 2019; Accepted: 26 September 2019; Published: 2 October 2019

\begin{abstract}
Heat is the deadliest meteorological hazard; however, those exposed to heat often do not feel they are in danger of heat-health effects and do not take precautions to avoid heat exposure. Socioeconomic factors, such as the high cost of running air conditioning, might prevent people from taking adaption measures. We assessed via a mixed-methods survey how residents of urban Knoxville, Tennessee, $(n=86)$ describe and interpret their personal vulnerability during hot weather. Thematic analyses reveal that many respondents describe uncomfortably hot weather based on its consequences, such as health effects and the need to change normal behavior, which misaligns with traditional heat-communication measures using specific weather conditions. Only $55 \%$ of those who perceived excessive heat as dangerous cited health as a cause for concern. Respondents who have experienced health issues during hot weather were more likely to perceive heat as dangerous and take actions to reduce heat exposure. Social cohesion was not a chief concern for our respondents, even though it has been connected to reducing time-delayed heat-health effects. Results support using thematic analyses, an underutilized tool in climatology research, to improve understanding of public perception of atmospheric hazards. We recommend a multi-faceted approach to addressing heat vulnerability.
\end{abstract}

Keywords: heat; heat perception; heat adaptation

\section{Introduction}

Excessive heat is increasing in many places as a result of global climate change. Average annual temperatures have increased by $0.7^{\circ} \mathrm{C}$ over the last 30 years in the contiguous United States, and they are expected to continue to increase by at least $1.2^{\circ} \mathrm{C}$ by 2050 [1]. In the southeastern United States, heatwaves are likely to become more frequent and intense, hot days are expected to become warmer, and the warm season is expected to be longer [1], exposing individuals in these areas to excessive heat and heat-related illnesses.

People are differentially exposed to heat. Urban areas change the way that wind, water and energy move through the area, trapping more heat near the surface [2]. This results in a phenomenon called the Urban Heat Island, which exposes urban residents to higher temperatures than rural residents, especially at night [2]. Heat exposure also varies within an urban area. For example, a location with a greater building density is likely to be warmer in the evening than one with a lower building density [3,4]. Meanwhile, an area with more vegetation, and thus higher amounts of evapotranspiration, is likely to have a higher heat index, the combined effect of temperature and humidity, than an area with less vegetation [5]. At an even smaller scale, an individual living or working in an upper floor of a building may be more exposed to heat that rises and persists in the upper floors of a building [6]. 
Additionally, those who work outside or in buildings without air conditioning or efficient air flow are more exposed to heat than those who work in a temperature-regulated environment $[7,8]$.

Heat is the deadliest metrological hazard [9]. Health effects of heat exposure include heatstroke, heat exhaustion, muscle cramps, and dehydration $[10,11]$. Those with pre-existing health issues can experience heat-related comorbidities, such as cardiovascular and respiratory difficulties and mental health disorders [6,11]. Heat exposure [12] and heat-related illnesses [13] are more likely on days that are at or near average temperature as individuals are more likely to take actions to reduce heat-health risks during extreme heat events. Those not acclimatized to heat or with a reduced ability to thermoregulate, such as children and the elderly, are more at risk for heat-related illnesses [6,14], whereas those who report good health are less likely to experience heat-related illnesses [15]. Likewise, individuals with higher income and more social cohesion are less likely to report heat-related illnesses [15].

People can use heat adaption methods to reduce exposure to high temperatures and humidity and minimize health risks. Examples of these adaption methods include using air conditioning, going to a cooler location, wearing lightweight clothing, and staying hydrated. Many factors affect the heat adaption actions that individuals take. Those living in unsafe areas are less likely to open their windows because of fear of crime [6,16]. Other residents may not have access to or be willing to use air conditioning, citing the high cost of running and repairing units [6,17]. Still others are not aware of what actions to take to avoid heat exposure, are not aware of heat events, or are unsure whether they are at risk for heat-related illnesses $[18,19]$.

Heat-related education and personal perception of the dangers of heat also affect the heat adaption actions taken. Individuals often do not perceive extreme heat as a hazard. Many individuals who live in a warm climate feel they are sufficiently acclimatized to heat so it is no longer a concern [18]. When individuals do not consider themselves at risk for heat-related illnesses, they are less likely to take measures to protect themselves $[18,20]$. Despite being more prone to heat-related illnesses, the elderly often do not see themselves at risk and take "common sense" actions during heat events, such as using fans [19], which can be an ineffective means for cooling and for reducing heat-health issues [21]. At the same time, having been negatively affected by a heat event, or knowing someone else who has, tends to increase an individual's risk perception [22] and increase their use of adaption methods.

Public opinions on heat risk and adaption actions have been studied using surveys in several cities in the United States [18,21]. Sheridan [21] noted that, while most of the participants in his study were aware of a heat event, they were less aware of what adaption actions they should take. Only half of those surveyed changed their behavior because of the heat [21]. The most common adaption actions taken by participants were avoiding the outdoors and using air conditioning [21]. In Phoenix, Arizona, individuals were more likely to feel they are at risk to excessive heat if an excessive heat warning is issued [18]. Socioeconomic characteristics, such as race, income, and age, played a role in whether individuals took adaption actions when they were aware of an excessive heat warning [18].

Using a mixed-methods survey for such studies expands the range of information usually obtained from exclusively qualitative or quantitative surveys [23,24]. Social measures, power relations, and perception cannot be easily measured through quantitative surveys [25]. In quantitative surveys, responses are required to fit into specific, researcher-defined categories. Perception studies focusing on climate $[19,20]$ and heat [21] that use mixed-methods interviews and phone surveys have provided more elaborate responses on social structures, such as what barriers exist for adaptation to hazards, as well as perceptions of hazards from participants. These studies demonstrate the potential for mixed-method surveys to obtain data that is deeper in information, though perhaps less extensive in study size, than quantitative surveys [26].

We use a survey containing a mix of open-ended and single- and multi-select questions to assess how residents of Knoxville, Tennessee, describe, experience, perceive, and adapt to heat. Specifically, we aim to answer four research questions: (1) how do respondents describe uncomfortably hot weather; (2) how do respondents perceive heat danger; (3) what health effects do respondents typically experience during hot weather; and (4) how do respondents adapt to hot weather? The significance of 
this work is to expand upon the limited research using combined qualitative and quantitative analyses to understand how heat affects urban residents' health and what motivates them to take adaption actions during heat events.

\section{Experiments}

We distributed a community survey between June and November 2017 in Knoxville, Tennessee (Figure 1). Knoxville is a mid-sized city in the southeast United States. The estimated population of the metropolitan area is 868,546 [27]. The city is located in a valley between Great Smoky Mountains to the east and the Cumberland Plateau to the west. Knoxville consists of a small urban core, with decreasing building density and height moving away from the urban core. The city has extensive urban sprawl, a confluence of major highways, and a major river running through it.

Knoxville has a humid subtropical climate, with an average high temperature during the warmest month (July) of $31.1^{\circ} \mathrm{C}$ and average low temperatures during the warmest month of $25.5-26.1^{\circ} \mathrm{C}$ [28]. The climate in eastern Tennessee is influenced by the surrounding topography and thus is slightly cooler than other areas in the southeastern United States, as seen in data from the National Oceanic and Atmospheric Administration [29]. As a mid-sized city, Knoxville does not likely experience as strong of an urban heat island signal as larger cities. Having a smaller heat island influence and a slightly cooler climate increases Knoxville resident's thermal comfort as compared to other cities in this region, such as Atlanta, Georgia, and Nashville, Tennessee. However, this reduced exposure likely results in less acclimatization to high heat and humidity. As criteria for issuing a heat advisory is based on acclimatization, heat advisory criteria varies by location [30]. In Knoxville, the National Weather Service issues heat advisories when the forecast indicates there will be a daytime heat index greater than $103^{\circ} \mathrm{F}\left(39.4^{\circ} \mathrm{C}\right)$ and nighttime temperatures remaining above $75^{\circ} \mathrm{F}\left(23.9^{\circ} \mathrm{C}\right)$ for two or more consecutive days [31]. Knoxville's residents are also at risk to several types of meteorological hazards, including severe convective weather, winter precipitation, flooding, and heatwaves.

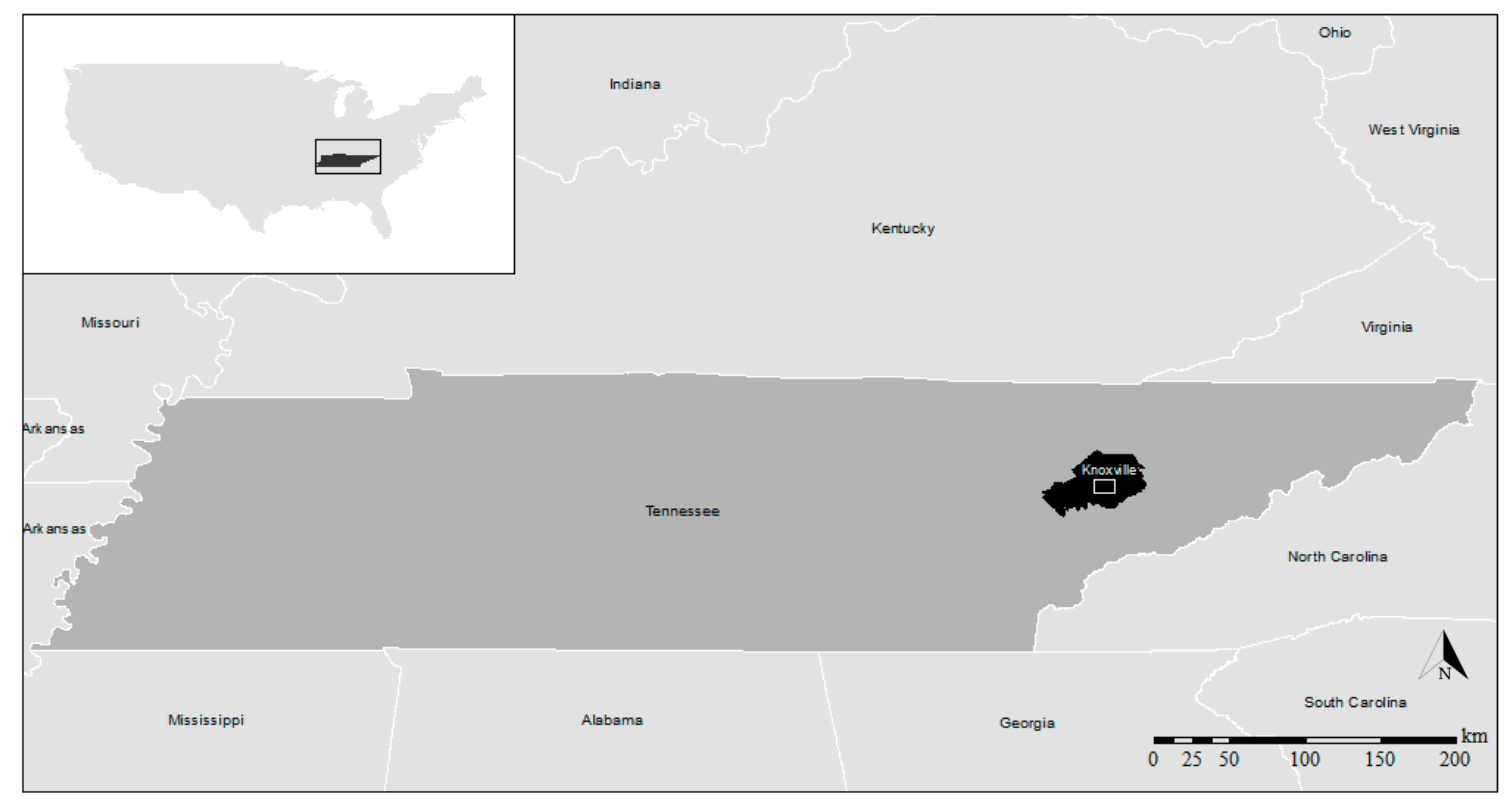

Figure 1. Location of Knoxville, Tennessee, within the United States of America.

The survey was distributed both electronically and in hardcopy (Supplementary Material). It consisted of qualitative and quantitative questions aimed to determine the respondents' demographic and socioeconomic characteristics, housing information, use of heat adaption and mitigation methods, understanding of meteorological hazards and heat-health effects during past heat events, and social cohesion. 
To recruit participants, we generally targeted three neighborhoods in Knoxville, including West Hills, Vestal, and Burlington. These neighborhoods are outside the urban core but within a 5-10 min drive of downtown. Of these neighborhoods, Burlington has the highest population density, Vestal has the lowest mean income, and West Hills has the highest mean income and lowest population density [32]. These specific neighborhoods were chosen because they consist of a range of incomes, offer a diverse population, and have varying population densities [5]. They have also been shown to experience different heat indices, with higher-income and lower-density neighborhoods experiencing higher heat indices because of increased vegetation [5]. We did not include "neighborhood" as a predictive variable in our study because specific neighborhood boundaries in Knoxville were, at the time of data collection, not clearly defined by the city. Instead, we targeted specific neighborhoods to ensure we had variance in our data. We recruited participants over the age of 18 by (1) attending two neighborhood association meetings in June 2017 and one community group meeting in November 2017, (2) going door to door in the neighborhoods, (3) approaching people in neighborhood parks, and (4) minimally using snowball and convenience sampling.

In total, 86 surveys were collected. Respondents at meetings were given a choice between taking the survey electronically on their own time or filling out a paper survey at the meeting. All other participants were asked to fill out a paper survey. Submission of the electronic survey implied informed consent, whereas those who filled out a paper survey signed a detached informed consent form. All study procedures were approved by the University of Tennessee, Knoxville Institutional Review Board (UTK IRB-17-03670-XP).

Participants and all others who were eligible to take the survey were able to enter a raffle to win one of twenty \$20 VISA gift cards. Raffle entries were not connected to the completed surveys to ensure anonymity. Names were randomly drawn using a random-number generator and raffle winners were contacted and mailed their gift cards.

Survey data were entered into Microsoft Excel and inspected for inconsistencies or lack of responses. One respondent (1.2\%) selected "prefer not to answer" in response to racial or ethnic background and four respondents (4.7\%) selected "prefer not to answer" in response to providing their household income. Responses of "prefer not to answer" were removed, as needed. All respondents provided an answer to all prompted survey questions, resulting in a $100 \%$ response rate for the other survey questions. Each survey was cross checked to ensure that answers were consistent. For instance, if a respondent said that they only lived in Tennessee but later indicated that they lived in the southeastern United States for less than 5 years, we would have discarded the survey to avoid inaccuracies. No inconsistencies were found and all 86 surveys were used for these analyses.

Descriptive statistics were used to delineate socioeconomic and demographic categorical answers-those where respondents had several options to choose from (Table 1). Respondents ranged in age from $18-65$ and over, with $87.2 \%$ of respondents being $18-59$. The majority $(69.0 \%)$ of respondents identified as female, which is higher than Knoxville's $52.1 \%$ female population [33]. Approximately $49.0 \%$ of respondents had earned a higher education degree, which is higher than the $31.4 \%$ of Knoxville's population that have earned a Bachelor's degree or higher [33]. These trends in participation are not uncommon as more educated individuals [34] and women [34,35] are more likely to respond to surveys. Thus, our results are biased towards females and individuals who are more educated than the general population and may have more knowledge of or exposure to heat adaption education. The majority (64.0\%) of respondents also identified as white, $24.4 \%$ of respondents identified as Black or African American, and 9.4\% identified as either Asian or Hispanic. Comparatively, Knoxville's population in 2018 was 75.2\% white, 17.5\% Black or African American, and 2.1\% Asian [33]. A higher minority response rate likely occurred because of the targeted neighborhoods, with Vestal and Burlington having higher minority populations than West Hills. 
Table 1. Demographic and socioeconomic characteristics of survey respondents.

\begin{tabular}{|c|c|c|}
\hline Characteristic & Count & Percent \\
\hline \multicolumn{3}{|l|}{ Age } \\
\hline $18-29$ & 21 & 24.4 \\
\hline 30-39 & 29 & 33.7 \\
\hline $40-49$ & 13 & 15.1 \\
\hline $50-59$ & 12 & 14.0 \\
\hline $60-65$ & 6 & 7.0 \\
\hline Over 65 & 5 & 5.8 \\
\hline \multicolumn{3}{|l|}{ Sex } \\
\hline Male & 27 & 31.4 \\
\hline Female & 59 & 68.6 \\
\hline \multicolumn{3}{|l|}{ Race/Ethnicity } \\
\hline Asian & 4 & 4.7 \\
\hline Black or African American & 21 & 24.4 \\
\hline Hispanic & 4 & 4.7 \\
\hline White & 55 & 64.0 \\
\hline Prefer not to answer & 2 & 2.3 \\
\hline \multicolumn{3}{|l|}{ Annual Household Income } \\
\hline Under $\$ 20,000$ & 22 & 25.6 \\
\hline$\$ 20,000-\$ 40,000$ & 23 & 26.7 \\
\hline$\$ 40,000-\$ 60,000$ & 18 & 20.9 \\
\hline$\$ 60,000-\$ 80,000$ & 9 & 10.5 \\
\hline$\$ 80,000-\$ 100,000$ & 5 & 5.8 \\
\hline Over $\$ 100,000$ & 5 & 5.8 \\
\hline Prefer not to answer & 4 & 4.7 \\
\hline \multicolumn{3}{|l|}{ Highest Level of Education Completed } \\
\hline Less than high school & 2 & 2.3 \\
\hline High school diploma or equivalent & 15 & 17.4 \\
\hline Post secondary, non-degree award & 6 & 7.0 \\
\hline Some college, no degree & 21 & 24.4 \\
\hline Associate's Degree & 5 & 5.8 \\
\hline Bachelor's Degree & 25 & 29.1 \\
\hline Master's Degree & 10 & 11.6 \\
\hline Doctoral or Professional Degree & 2 & 2.3 \\
\hline \multicolumn{3}{|l|}{ Employment Status } \\
\hline Employed full-time & 42 & 48.8 \\
\hline Employed part-time & 25 & 29.1 \\
\hline Homemaker or stay at home parent & 6 & 7.0 \\
\hline Retired & 9 & 10.5 \\
\hline Unemployed & 4 & 4.7 \\
\hline \multicolumn{3}{|l|}{ Student Status } \\
\hline Not a student & 66 & 76.7 \\
\hline Part-time student & 8 & 9.3 \\
\hline Full-time student & 12 & 14.0 \\
\hline
\end{tabular}

Categories were collapsed to ensure there were enough samples in each category to perform statistical analyses, specifically the need for an expected value of five or more for the Chi-squared tests. The new age categories were 18-29, 30-49, and over 50. The new annual household income categories were under $\$ 20,000, \$ 20,000-\$ 40,000$, and over $\$ 40,000$. The new categories for the highest level of education completed were high school graduate/GED or less, some college to Associate's degree, and Bachelor's or higher. The new employment categories were full-time, part-time, and other (including retired, homemaker, and unemployed). Student status was recategorized as not a student and student (including part-time and full-time). We recategorized acclimatization to create two 
categories: More than 10 years of residency in the southeastern U.S. and 10 or fewer years of residency in the southeastern U.S. The new social cohesion categories were cohesive (including survey responses of somewhat confident and very confident that they had social support) and not cohesive (including survey responses of not too confident and not confident at all that they had social support). Finally, self-reported health status was recategorized as excellent, good (including very good and good), and fair to poor.

We used hierarchical coding to analyze the open-ended survey responses. Each response was categorized into primary themes and then further into secondary themes [36]. Some responses were included in multiple primary and secondary themes as they contained information that could potentially contribute to the data analysis in more than one context [36]. For example, for the question, "Why do you feel that hot days and heatwaves are dangerous to you?" a participant responded:

\section{"I work outside often, and I have read about how prolonged exposure to extreme heat can lead to kidney problems through repeated dehydration."}

This was placed under both the "exposure (outside/work)" and "health" primary themes. This response was further assigned a secondary code of "dehydration." Some of the themes that resulted from our thematic data analysis were applied to our dataset as categories to enable us to perform a statistical analysis for information that was provided in a qualitative format.

We used multiple logistic regression to determine whether socioeconomic and demographic characteristics affected the themes that resulted from our hierarchical coding of respondents' descriptions of hot days. Multiple logistic regression was also used to determine if the amount of time spent in the southeastern U.S. (acclimatization) affected the themes that resulted from our hierarchical coding of respondents' descriptions of hot days. Multiple logistic regression was chosen for these analyses because a categorical dependent variable was being compared to multiple levels of categorical independent variables.

Chi-squared was used to test the associations between individual characteristics/perceptions and (1) reported heat-health effects and (2) reported heat adaption behaviors. Chi-squared was chosen as we were comparing one characteristic or perception category to one heat-health effect or adaption behavior, as applicable. The Yates correction was used to reduce the tendency of Chi-squared test to bias the $p$-value in small samples [37]. To identify whether responses occurred at the expected frequency, given the population, the difference between the frequency expected for each response (expected values) and the frequency that was observed in our study (observed values) was analyzed to identify whether responses occurred.

\section{Study Limitations}

Sampling urban neighborhoods can introduce potential problems because there is no efficient and practical way to collect information on all behaviors and perspectives in a large group of people $[38,39]$. This was considered during data analysis. Snowball sampling was used with care to avoid overrepresentation of specific personalities or groups [38]. To account for these limitations, we used purposive sampling instead of random, representative, convenience, or stratified sampling procedures [40]. Purposive sampling allows for efficient data collection while maintaining a low level of bias [40].

This study was based on a small sample size. This was partly because we physically went out to collect data, instead of using phone, email, or mail to distribute the surveys. The small sample size was also reflective of our decision to use a mixed-methods approach including qualitative data analysis, which allowed us to delve deeper into our participants' responses, rather than casting a wide net as seen in other studies using quantitative data. However, a smaller sample size could result in fewer significant results during statistical analyses.

We collected data from June through November, which might result in a seasonal bias in the survey responses $[36,41]$. For example, respondents that took the survey during the warm season 
might be more concerned about heat-related issues than someone who took the survey during the late fall, when the weather was cooling down.

\section{Results and Discussion}

\subsection{How Do Respondents Describe Uncomfortably Hot Weather?}

Respondents were asked "How do you describe uncomfortably hot weather?" and their open-ended answers were placed into five primary themes (Table 2). Of the five major themes, the most common was for respondents to describe uncomfortably hot weather in terms of specific weather conditions. To a lesser degree, participants also described uncomfortably hot weather as times when they needed to alter their normal behaviors and activities, when they were generally uncomfortable, and when they experienced health effects, such as breathing difficulties and sweating. Approximately $10 \%$ of participants reported that they were generally indifferent to heat. According to our multiple logistic regression analyses, citing being indifferent to heat was not significantly $(p<0.05)$ affected by (1) socioeconomic characteristics, (2) demographic characteristics, (3) self-reported health status, or (4) acclimatization to heat.

Table 2. Examples of open-ended responses to the survey question, "How do you describe uncomfortably hot weather?" $(n=86)$. As some responses fit into multiple themes, the total number and percentage of responses described below is greater than 86 samples and $100 \%$.

\begin{tabular}{|c|c|c|c|c|c|}
\hline & $\begin{array}{l}\text { Specific Weather } \\
\text { Conditions }\end{array}$ & $\begin{array}{c}\text { Change in Activities and } \\
\text { Normal Behavior }\end{array}$ & $\begin{array}{c}\text { General } \\
\text { Discomfort }\end{array}$ & Health Effects & Indifference to Heat \\
\hline $\begin{array}{l}\text { Total number } \\
\text { and percent of } \\
\text { responses }\end{array}$ & $\begin{array}{l}n=45 \\
52.3 \%\end{array}$ & $\begin{array}{l}n=16 \\
18.6 \%\end{array}$ & $\begin{array}{l}n=11 \\
12.8 \%\end{array}$ & $\begin{array}{l}n=9 \\
10.5 \%\end{array}$ & $\begin{array}{c}n=9 \\
10.5 \%\end{array}$ \\
\hline \multirow{3}{*}{$\begin{array}{l}\text { Example } \\
\text { responses }\end{array}$} & $\begin{array}{l}\text { "Anything above } \\
95^{\circ} . "\end{array}$ & $\begin{array}{l}\text { "It makes me feel like I can } \\
\text { not [sic] move or act like } \\
\text { normal people anymore." }\end{array}$ & $\begin{array}{l}\text { "Uncomfortable } \\
\text { in pants." }\end{array}$ & “Dizzy, sweating." & $\begin{array}{l}\text { "I'm rarely } \\
\text { uncomfortable in } \\
\text { heat." }\end{array}$ \\
\hline & $\begin{array}{l}\text { "More than } 90^{\circ} \mathrm{F} \\
\text { and } 90 \% \text { humidity." }\end{array}$ & $\begin{array}{c}\text { "When it's too hot to hike, } \\
\text { etc." }\end{array}$ & "Awful." & $\begin{array}{l}\text { "Anytime it is hard } \\
\text { to breathe." }\end{array}$ & $\begin{array}{l}\text { "I am more } \\
\text { comfortable when it } \\
\text { is hot." }\end{array}$ \\
\hline & $\begin{array}{l}\text { "Summer- } \\
\text { July/August." }\end{array}$ & $\begin{array}{c}\text { "Too hot to have the baby } \\
\text { out." }\end{array}$ & “Ugh!!!” & $\begin{array}{l}\text { "When you get } \\
\text { heat exhaustion." }\end{array}$ & "I am used to hot." \\
\hline
\end{tabular}

We looked further into our most commonly assigned theme, which was defining heat using specific weather conditions. Of the 45 responses that fit into this category, describing uncomfortably hot weather as temperatures above $90^{\circ} \mathrm{F}(n=13)$ or humid $(n=14)$ was most common. Six respondents described uncomfortably hot weather as temperatures between 80 and $89^{\circ} \mathrm{F}$. Thirteen respondents answered in a way that we described as "other." Examples of responses from the "other" category include "Sub Saharan Africa hot," "Searing oven," "Heat waves," and "Late summer." According to our multiple logistic regression analyses, describing uncomfortably hot weather as a specific weather condition was not significantly $(p<0.05)$ affected by $(1)$ socioeconomic characteristics, $(2)$ demographic characteristics, (3) self-reported health status, or (4) acclimatization to heat.

Little research has been published on how the public describes hot weather. Currently, the National Weather Service defines excessive heat based on specific heat indices and temperatures [42]. While some respondents described hot weather based on specific temperatures and humidity levels, others equated hot weather to health effects, changes they needed to make to their normal activities, or general discomfort. Warning the public of excessive heat by using specific terminology, such as temperature, humidity, and heat index, may not be an effective way of communicating to those that do not use 
these terms to define dangerously hot weather. When specifically looking at ways to improve heat education, understanding how to describe heat to the public in a meaningful way is crucial to convey the importance of heat-related risks and helping the public understand how to recognize excessive heat conditions. Additionally, high resolution weather forecasting using smartphone apps is emerging as a way to provide forecasting for thermal comfort in a specific location and allows users to understand their risk of heat exposure in different environmental and atmospheric conditions [43].

Only one respondent mentioned heat-related advisories as a way of defining uncomfortably hot weather by saying:

\section{"If the meteorologist tells me to be careful."}

Other studies found that heat warnings, when heavily covered by the media, are an effective way of warning individuals of the risk of heat exposure [21]. However, Kalkstein and Sheridan [18] found that apathy to heat exposure was partly because of a lack of media coverage. Nearly $11 \%$ of our respondents were apathetic to uncomfortably hot days and many reported that their lack of concern was because they were acclimatized to excessive heat, although this relationship was not statistically significant, which is likely a result of our small sample size.

\subsection{How Do Respondents Perceive Heat Danger?}

We asked respondents "Which weather event do you feel is the biggest threat to you?". Respondents could choose from (1) drought, (2) extreme cold, (3) extreme heat, (4) flooding, (5) hail, (6) ice storms and snow, (7) severe storms, (8) tornadoes, (9) all of the above, or (10) none. Only one respondent indicated that no meteorological hazards are dangerous to them. Overwhelmingly, respondents felt that severe storms and tornadoes (44.2\%) and cold-related hazards (34.9\%) were most dangerous. Only $14.0 \%$ of respondents indicated that they felt extreme heat was the biggest threat to them. Excessive heat is the deadliest meteorological hazard; however, heat events do not have the "awe factor" of other hazards, such as tornadoes and ice storms, and thus might be perceived as less dangerous [18,44]. Likewise, heat events are more common in our study area than cold events, which may produce feelings of apathy as respondents may see excessive heat as a common event without much risk.

We asked respondents the single-select question "How dangerous do you think hot days and heatwaves are to you?". If respondents indicated that they felt that extreme heat was a little, somewhat, or very dangerous to them $(n=75)$, they were asked the open-ended question, "Why do you feel hot days and heatwaves are dangerous to you?". Analyses of their answers resulted in six themes, the most common being health, exposure, and general danger (Table 3). The themes of age, general discomfort, and social cohesion only included $6.0 \%, 8.6 \%$, and $2.8 \%$ of responses, respectively, and are not discussed here. Exposure was cited as a reason why hot days and heatwaves are dangerous, with sub-themes including being outside during hot weather (50.0\% of respondents who cited exposure) and being exposed while at work (37.5\% of respondents who cited exposure). Multiple logistic regression results suggest that socioeconomic and demographic characteristics, self-reported health status, and acclimatization to heat did not have a statistically significant $(p<0.05)$ effect on respondents' reasoning for why they felt hot days and heatwaves were dangerous to them, which could be a result of our small sample size.

Common sub-themes of health dangers cited by respondents were dehydration $(35.9 \%$ of respondents who cited health as why heat is dangerous), heat stroke and exhaustion $(20.5 \%)$, respiratory issues $(20.5 \%)$, and general health dangers (33.3\%). Examples of general health dangers included, "can be deadly," "without adequate elements such as shade and water, hot days can pose a serious health risk to anyone," and "you can overheat."

Only one respondent noted mental health issues resulting from heat events:

"I find that my mental health is affected by having to find shelter from the heat. Being outside for extended periods during the hottest part of the year can lead to feeling physically ill from exhaustion/dehydration, and being confined inside to escape the heat becomes mentally draining." 
Mason et al. [15], however, found that more than 55\% of Knoxville residents in lower- to moderate-income neighborhoods experienced mental health effects from summer heat. We did not specifically provide "mental health effects" as an option for the categorical response options to the question of, "What health effects do you typically experience during hot weather?" (see Section 3.3). These differing results suggest that the mental health effects of heat may not be well known by the public and they may not connect the ideas of heat exposure and mental health if unprompted. This could be in part because heat-related illnesses are not well reported by the media [44].

In a previous study, increased social cohesion, or the amount of social support an individual feels that they have, resulted in a decreased report of physical or mental impacts from summer heat [15]. Only two of our respondents reported a lack of social cohesion as a reason why they feel excessive heat is dangerous to them by both saying, "I live alone." This theme was more prominent in the Mason et al. [15] study. Increasing the social cohesion of a neighborhood by developing systems to check on one another during heat and other dangerous weather events is one potential way to reduce delayed heat-health impacts for some individuals [15,45], yet our research shows that for many others social cohesion is not a primary concern and the effects of social cohesion may vary by neighborhood, socioeconomic, and health characteristics.

Table 3. Examples of open-ended responses to the survey question, “Why do you feel hot days and heatwaves are dangerous to you?" $(n=70)$. Themes that included less than $10 \%$ of responses are not included here.

\begin{tabular}{|c|c|c|c|}
\hline & Health & $\begin{array}{c}\text { Exposure } \\
\text { (Outside/Work) }\end{array}$ & General Danger \\
\hline $\begin{array}{l}\text { Total number and } \\
\text { percent of responses }\end{array}$ & $\begin{array}{l}n=39 \\
55.7 \%\end{array}$ & $\begin{array}{l}n=16 \\
22.9 \%\end{array}$ & $\begin{array}{c}n=8 \\
11.4 \%\end{array}$ \\
\hline \multirow{5}{*}{ Example responses } & "It's easy to get dehydrated." & $\begin{array}{l}\text { "I am exposed to them } \\
\text { [heatwaves] more often } \\
\text { than any other weather } \\
\text { activity." }\end{array}$ & $\begin{array}{c}\text { "They are dangerous, but } \\
\text { I take measures to } \\
\text { protect myself." }\end{array}$ \\
\hline & “Risk for heat exhaustion." & "I walk to work." & $\begin{array}{l}\text { "Extreme weather is } \\
\text { dangerous to everyone if } \\
\text { proper precautions, etc. } \\
\text { are not taken." }\end{array}$ \\
\hline & $\begin{array}{l}\text { "I have heart problems and have } \\
\text { trouble breathing when hot." }\end{array}$ & "Too hot to work." & $\begin{array}{l}\text { "Heat is dangerous to } \\
\text { everyone." }\end{array}$ \\
\hline & $\begin{array}{l}\text { "... I get migraines from the } \\
\text { heat occasionally." }\end{array}$ & $\begin{array}{c}\text { "I enjoy running and } \\
\text { hiking so I am outdoors } \\
\text { a lot." }\end{array}$ & $\begin{array}{l}\text { "Heatwaves make } \\
\text { normal activities } \\
\text { dangerous." }\end{array}$ \\
\hline & $\begin{array}{l}\text { "I work outside often, and I } \\
\text { have read about how prolonged } \\
\text { exposure to extreme heat can } \\
\text { lead to kidney problems } \\
\text { through repeated dehydration." }\end{array}$ & $\begin{array}{l}\text { "Makes it hard to be } \\
\text { outside." }\end{array}$ & $\begin{array}{c}\text { "Not as dangerous as } \\
\text { cold but extreme weather } \\
\text { is a risk." }\end{array}$ \\
\hline
\end{tabular}

Nearly $23 \%$ of respondents cited exposure while outside and/or while at work as a reason why they feel excessive heat is dangerous. Occupational studies using personal temperature sensors indicated that higher temperatures, exposure to direct sunlight, and exposure to heat from machinery led to outdoor workers being exposed to excessive heat $[7,8]$. Options for reducing heat-related illnesses at work include periodically moving to temperature-regulated locations to reduce exposure, staying hydrated, seeking shade, reducing physical exertion, and allowing time to acclimatize to excessive heat $[7,8,46]$. While the Occupational Safety and Health Administration, the National Institute for Occupational Safety and Health, and other agencies recommend specific ways in which employers should address employee heat exposure [46], our study shows that occupational heat exposure is still a concern in Knoxville. Studies assessing employee exposure to high temperatures and humidity in 
specific work environments could help employers ensure they are reducing their employees' risk for heat-related illnesses.

\subsection{What Health Effects Do Respondents Typically Experience during Hot Weather?}

We asked respondents "What health effects do you typically experience on hot days?". The options respondents were able to choose from included (1) sweating, (2) headache, (3) dehydration, (4) nausea, (5) confusion, (6) muscle cramps, (7) no effects, and/or (8) other symptoms (open ended). Sweating, dehydration, headaches, and muscle cramps were most reported as being experienced by respondents on hot days (Table 4). Only one respondent reported having no health effects on hot days. No respondents reported that they experienced nausea or confusion.

The respondent's work status was only associated with experiencing muscle cramps. Fewer fulland part-time workers experienced muscle cramps than expected. Conversely, more participants in our "other" work category experienced muscle cramps than expected, likely because this category includes those more prone to heat-related illnesses, such as retired individuals at an advanced age. Work status did not affect the other variables, showing that headaches, dehydration, and sweating affect a larger and broader population.

Table 4. Percent of respondents that reported health effects and Chi-squared results for the associations between reported heat-health effects and personal characteristics and perceptions $(n=85)^{1}$.

\begin{tabular}{|c|c|c|c|c|}
\hline & Sweating & Dehydration & Headaches & Muscle Cramps \\
\hline Percent of respondents that reported health effect(s) & $\begin{array}{l}n=83 \\
96.5 \%\end{array}$ & $\begin{array}{l}n=55 \\
64.0 \%\end{array}$ & $\begin{array}{l}n=20 \\
23.3 \%\end{array}$ & $\begin{array}{l}n=20 \\
23.3 \%\end{array}$ \\
\hline $\begin{array}{l}\text { Work } \\
\text { Full-time } \\
\text { Part-time } \\
\text { Other }\end{array}$ & 0.909 & 3.622 & 4.174 & $\begin{array}{c}16.442^{* * *} \\
-3.8 \\
-2.8 \\
6.5\end{array}$ \\
\hline $\begin{array}{l}\text { Social cohesion } \\
\text { Cohesive } \\
\text { Not cohesive }\end{array}$ & 0.412 & 0.540 & $\begin{array}{c}9.001 * \\
-1.6 \\
2 \\
\end{array}$ & 0.995 \\
\hline $\begin{array}{l}\text { Whether or not respondents felt heat was dangerous } \\
\text { Yes } \\
\text { No }\end{array}$ & $\begin{array}{c}3.858^{*} \\
1.6 \\
-1.6\end{array}$ & $\begin{array}{c}5.650^{* *} \\
4 \\
-4\end{array}$ & 2.474 & 0.730 \\
\hline $\begin{array}{l}\text { Cited "health" as why heat is dangerous } \\
\text { Yes } \\
\text { No }\end{array}$ & $<0.001$ & $\begin{array}{l}4.501 * \\
4.7 \\
-4.7\end{array}$ & $\begin{array}{l}3.944^{*} \\
4.2 \\
-4.2\end{array}$ & 0.730 \\
\hline
\end{tabular}

Social cohesion was only associated with headaches and, as shown by the $p$-value and a small difference in observed versus expected values, it is not a notable finding. Thus, social cohesion, in this study, did not prove to be highly related to the health effects that we tested. This is likely because our respondents did not connect their social cohesion with heat-health concerns or do not feel that they are at risk for heat-health issues. Browning et al. [45] found that structural characteristics and social trust affects the social cohesion of a neighborhood. We collected many of our surveys in a door-to-door manner and in community meetings and thus collected in spaces where there were increased structural characteristics, such as sidewalks and gathering areas, and greater social trust, such as in areas generally considered safe or within groups of individuals that were invested in their neighborhoods. This data collection pattern could have created a bias towards collecting information in areas with greater social cohesion.

Perceptions of heat and heat-health danger were each significantly related to two of the health effects, with those who think heat is dangerous and a health concern reporting more health effects than 
expected. An individual's perception of their risk for heat-related illnesses plays a significant role in whether respondents reported health effects during excessive heat. These perceptions may come from previous exposure to excessive levels of heat [22]. Respondents may be more sensitive to heat-health risks if they or someone they know has experienced the hazard before [22], and thus might be more likely to recognize or connect health effects to the hazard.

\subsection{How Do Respondents Adapt to Hot Weather?}

When asked "What behaviors or actions do you normally take during hot days and heatwaves?" the most common reported behaviors were using air conditioning $(86.0 \%)$, making an extra effort to stay hydrated $(80.2 \%)$, using fans $(50.0 \%)$, avoiding overexertion $(47.7 \%)$, seeking a cooler location $(46.5 \%)$, avoiding being outside $(45.3 \%)$, changing clothing $(34.9 \%)$, and using water features, such as splash pads and pools (22.1\%). Those that were found to be significantly associated to any of the personal characteristics or perception variables are listed in Table 5.

Table 5. Percent of respondents that reported behaviors and Chi-squared results for the associations between reported behaviors and personal characteristics and perceptions ${ }^{1}$.

\begin{tabular}{|c|c|c|c|c|}
\hline & $\begin{array}{l}\text { Avoiding over } \\
\text { Exertion }\end{array}$ & $\begin{array}{l}\text { Seeking Cooler } \\
\text { Location }\end{array}$ & $\begin{array}{c}\text { Avoiding } \\
\text { being Outside }\end{array}$ & $\begin{array}{l}\text { Use Water } \\
\text { Features }\end{array}$ \\
\hline $\begin{array}{l}\text { Number and percent of respondents } \\
\text { that reported behavior }\end{array}$ & $\begin{array}{l}n=41 \\
47.7 \%\end{array}$ & $\begin{array}{l}n=40 \\
46.5 \%\end{array}$ & $\begin{array}{l}n=39 \\
45.3 \%\end{array}$ & $\begin{array}{l}n=19 \\
22.1 \%\end{array}$ \\
\hline $\begin{array}{l}\text { Student } \\
\text { Yes } \\
\text { No }\end{array}$ & 1.768 & 0.169 & $<0.001$ & $\begin{array}{c}4.018^{*} \\
3.6 \\
-3.6\end{array}$ \\
\hline $\begin{array}{l}\text { Acclimatization } \\
\text { Less than } 10 \mathrm{yr} \\
\text { More than } 10 \mathrm{yr}\end{array}$ & 1.424 & 1.152 & 2.056 & $\begin{array}{c}4.030^{*} \\
3.9 \\
-3.9\end{array}$ \\
\hline $\begin{array}{l}\text { Health } \\
\text { Excellent } \\
\text { Good } \\
\text { Fair to poor }\end{array}$ & 1.715 & 0.587 & 3.705 & $\begin{array}{c}7.440^{*} \\
3.8 \\
0.3 \\
-4.1\end{array}$ \\
\hline $\begin{array}{l}\text { Whether or not respondents felt heat } \\
\text { was dangerous } \\
\text { Yes } \\
\text { No }\end{array}$ & 0.822 & $\begin{array}{c}7.583^{* *} \\
5.2 \\
-5.1\end{array}$ & $\begin{array}{c}6.328 * \\
1.0 \\
-1.0\end{array}$ & 0.100 \\
\hline $\begin{array}{l}\text { Cited "health" as why heat is dangerous } \\
\text { Yes } \\
\text { No }\end{array}$ & $\begin{array}{c}10.266^{* *} \\
0.9 \\
-0.9\end{array}$ & $\begin{array}{l}8.929 * * \\
5.1 \\
-5.1\end{array}$ & 0.100 & 0.693 \\
\hline
\end{tabular}

Using water features was significantly more common for those who have been in the southeastern U.S. less than 10 years, those in excellent or good health, and those who are students. Those who are not acclimatized to the weather are likely using water features more because it is a common-sense heat adaption method. Students, on the other hand, might use water features because it is cost efficient, with pools being generally available to students for free through their school or publicly for a minimal cost.

Seeking a cooler location was more common for respondents who perceived heat as dangerous and for those who cited heat-health concerns. Of the heat adaption behaviors that respondents chose from, seeking a cooler location was one of the most accessible and inexpensive options. This is also a common-sense behavior. Those with health concerns are likely using this adaption method to reduce their exposure and thus reduce the likelihood that they will experience heat-health effects. 
Respondents who did not alter their normal schedule on hot days were asked in an open-ended question, "Why do you not change or move daily activities on hot days?" (Table 6). There were three main themes for why they do not change their activities on hot days: (1) They are acclimatized to or well prepared for heat, (2) they cannot alter their schedule because of work or other factors, and (3) they do not normally spend time outside and are thus not exposed to changes in temperature.

The perception of a lack of heat danger and heat-health danger had the most effects on respondents not taking adaption actions. This pattern was also reported by Sheridan [21], Abrahamson et al. [19], and Toloo, Fitzgerald, Aitken, Verrall, and Tong [47]. Some individuals feel "pride" that they can handle uncomfortably hot weather [21]. Others simply do not see themselves as being at risk [19,21]. These perceptions can result in an individual not taking adaption actions to reduce exposure and thus potentially exposing themselves to heat-health risks. One opportunity to improve risk perception is to have media outlets inform their audience on which populations are vulnerable to heat-health risks during heat advisories and warnings [21].

Nearly one in 10 respondents could not or felt that they were unable to take adaption actions and were at a higher risk for heat-related illnesses. Individuals who could not alter their routine and felt they were acclimatized or "used to" heat would benefit from advanced heat-health education provided by the National Weather Service, city governments, or other outreach personnel. These educational opportunities should include the development of individual action plans, which could help those who simply do not want to alter their routines or feel that there are no other options but to keep with business as usual.

Table 6. Examples of open-ended responses to the survey question, "Why do you not change or move daily activities on hot days?" $(n=29)$.

\begin{tabular}{|c|c|c|c|}
\hline & $\begin{array}{c}\text { Acclimatized to Heat or } \\
\text { Well Prepared }\end{array}$ & Cannot Alter Schedule & $\begin{array}{l}\text { Does not Normally } \\
\text { Spend Time Outside }\end{array}$ \\
\hline \multirow{2}{*}{$\begin{array}{l}\text { Total number and } \\
\text { percent of responses }\end{array}$} & $n=11$ & $n=9$ & $n=7$ \\
\hline & $37.9 \%$ & $31.3 \%$ & $24.1 \%$ \\
\hline \multirow{3}{*}{ Example responses } & $\begin{array}{l}\text { "Am easily acclimated to } \\
\text { extreme heat/cold." }\end{array}$ & $\begin{array}{l}\text { "I walk a short distance } \\
\text { to my job." }\end{array}$ & $\begin{array}{l}\text { "I do not spend a lot of } \\
\text { time outside." }\end{array}$ \\
\hline & "Used to heat." & $\begin{array}{l}\text { "It would disturb my } \\
\text { routine." }\end{array}$ & $\begin{array}{c}\text { "Because I don't have to } \\
\text { be outdoors." }\end{array}$ \\
\hline & $\begin{array}{c}\text { "I feel safe as long as I } \\
\text { prepare." }\end{array}$ & $\begin{array}{c}\text { "Some activities cannot } \\
\text { be avoided." }\end{array}$ & “I don't go outside." \\
\hline
\end{tabular}

\section{Summary and Conclusions}

We used a mixed-methods survey to assess how respondents in Knoxville, Tennessee, describe, experience, perceive, and adapt to hot weather. This research adds to the small research base that uses qualitative analyses in climatology research. Our mixed-methods approach allowed for the statistical analyses necessary to gain insight into broad concepts, such as whether respondents felt heat was dangerous, while the qualitative thematic coding shed light on deeper ideas, such as why they felt heat was dangerous, supporting the need for education on why heat is dangerous. While more significant patterns might emerge from statistical analyses of a larger sample size, small-scale studies and qualitative research allows for respondents to provide information outside of set boundaries and expand our knowledge base beyond what has been previously studied and in ways we may not have hypothesized. For example, when asking respondents why they did not change their behavior to avoid heat exposure, some simply felt that they were not able to change their routine because, for instance, their transportation to work is walking or they do not feel comfortable changing their routine. These ideas would not have been accessible using single- or multi-select questions. Future survey-related climatology research should aim to include some open-ended response questions to gain insight into ideas and themes that researchers may not currently be aware of. 


\subsection{How Do Respondents Describe Uncomfortably Hot Weather?}

Our results for this research question demonstrated discordance between traditional heat communication methods and the needs of residents, which may affect how individuals perceive heat danger. One example of these misaligned communication methods is that many of our respondents defined heat primarily based on changes they needed to make to their normal routine. Those who describe heat in ways other than quantitative temperature and humidity measurements would better understand their risk for exposure when being presented with adaption information rather than specific weather conditions. Communication methods have recently shifted away from the traditional method of using specific weather conditions to define heat risk, and now include more information on the generalized adaptive behaviors individuals should take. Based on our results, we recommend a continued systemic change to heat-related education and media coverage.

First, we recommend describing heat based on a change in behaviors or consequences, as well as specific weather conditions. Traditional communication methods may not be effective across an entire population and may result in a misunderstanding of an individuals' risk for heat exposure and heat-health effects. Based on our survey, we recommend that the media inform their audience of heat-related risks by using specific weather conditions to outline heat danger, and by emphasizing health risks, vulnerable populations, and how people might need to change their normal routine to avoid heat exposure. While some National Weather Service offices have begun distributing infographics on social media to inform the public of excessive heat risk and heat-adaptive actions, this information does not typically contain information on the populations most at risk for heat-related illnesses. These infographics are also not usually distributed during normal weather conditions, when some individuals are more exposed to heat as they are taking less adaptive actions [12].

Second, heat-related education is needed to ensure individuals exposed to excessive heat understand whether they are part of a vulnerable population and are aware of the actions they can take to reduce their vulnerability [21]. Heat education provided by the media, the National Weather Service and similar agencies, city governments, and other outreach professionals could help change the public's perception of heat and who is at risk, thus increasing their willingness to take adaptive actions. These educational opportunities should include information on health risks, vulnerable populations, heat awareness, and adaption options to increase the prevalence of heat adaption activities. Heat education should also include individual action plans to ensure that the public understands appropriate ways to adapt to excessive heat before it occurs.

\subsection{How Do Respondents Perceive Heat Danger?}

Not all participants perceived heat as a danger. Should this sentiment exist on a broader scale, it would be imperative to increase public knowledge of the danger that heat possesses as the warm season is expected to become warmer and longer, and heatwaves are expected to become more frequent and intense. Social cohesion was not a primary concern to our respondents; however, it is an important aspect in reducing vulnerability to heat-health effects [15]. However, we collected surveys in situations and locations that promote social cohesion, which may not be representative of Knoxville residents as a whole. Programs to strengthen social cohesion in vulnerable neighborhoods could reduce time-delayed heat-health effects $[15,45]$. Increasing social trust and building more extensive neighborhood structures, such as sidewalks, are two methods of growing social cohesion in a neighborhood [45]. Additionally, increased heat education and opportunities to reduce heat exposure in the workplace is needed to ease the concern of occupational heat exposure that was reveled in this study. These opportunities could be in collaboration with the Occupational Safety and Health Administration, the National Institute for Occupational Safety and Health, and similar agencies. 


\subsection{What Health Effects Do Respondents Typically Experience during Hot Weather?}

Whether respondents experience health issues during excessive heat plays a notable role on their perception of heat danger and if they take heat adaption actions to avoid exposure. Our results suggest that, while the majority of survey respondents feel that excessive heat is at least somewhat dangerous to them, fewer respondents feel heat is a health risk. Respondents who perceive that heat is dangerous are more likely to recognize heat-related dangers and health risks and take actions to reduce heat exposure. Based on our results, reducing heat-related health problems needs to be addressed first through improving resident's understanding and perception of exposure to heat and who is at risk for heat-related illnesses, as discussed above.

\subsection{How Do Respondents Adapt to Hot Weather?}

All three previous research questions contribute to our understanding of how respondents adapt to hot weather. Our results show that heat danger perception plays a critical role in whether individuals take adaption actions and which actions they take, which will become more important as heatwaves and hot days become more frequent and intense with changing climate [1]. Respondents that do not perceive they are at risk for heat-related illnesses or are unable to alter their schedule are less likely to take adaption actions and are more vulnerable to heat-health issues. Individuals that experience heat-health issues are more likely to feel that heat is dangerous and take heat adaption actions, likely reducing their vulnerability to heat-health issues.

\subsection{Conclusions}

As presented above, the results from each of our research questions indicate that a multi-faceted approach to reducing heat vulnerability is needed as individuals within an urban area have varying concerns. Our results are based on a small sample, but we see clear ways to improve heat communication and heat adaption that could benefit Knoxville's residents, and potentially the larger public. Based on our results and the cited literature, we suggest the following as possible strategies to reduce heat exposure and related illnesses: (1) Increasing access to heat adaption methods, (2) strengthening social cohesion, (3) refining heat risk communication, and (4) changing the perception of heat-related dangers through community education.

However, the above recommendations for systemic changes will take resources, including time and financial support. We recommend first focusing on individual-level heat adaption methods, such as using air conditioning, seeking a cooler location, and using water features. Further research to understand how the public defines heat will increase the sample size, ensure that techniques for improving communication match the needs of the general public, help bolster media coverage, and strengthen heat education efforts. Future research on this topic could incorporate living conditions, including housing quality and condition; compare the frequency of illnesses reported to health care professionals and emergency rooms with the frequency of perceived illnesses; and make connections between heat perception, specific dates or months, and perception.

Supplementary Materials: The following are available online at http://www.mdpi.com/2073-4433/10/10/591/s1, Document S1: Survey.

Author Contributions: Conceptualization, A.L.H. and K.N.E.; Methodology, A.L.H. and K.N.E.; Funding acquisition, A.L.H.; Investigation, A.L.H.; Formal analysis, A.L.H. and K.N.E.; Writing-original draft, A.L.H.; Writing-review and editing, A.L.H. and K.N.E.

Funding: This research was funded by a University of Tennessee, Knoxville Thomas Graduate Fellowship awarded to Alisa L. Hass.

Acknowledgments: We appreciate the community members who graciously participated in this research. We thank Micheline Van Riemsdijk for her guidance in qualitative methods and developing the survey. We thank Erica Massengill for her assistance in collecting surveys. We also thank Hass' dissertation committee members, Sally Horn, Solange Munoz, and Jiangang Chen, and the anonymous manuscript reviewers for their valuable comments and suggestions to improve this manuscript. 
Conflicts of Interest: The authors declare no conflict of interest. The funders had no role in the design of the study; in the collection, analyses, or interpretation of data; in the writing of the manuscript, or in the decision to publish the results.

Ethical Statement: All subjects gave their informed consent for inclusion before they participated in the study. The study was conducted in accordance with the Declaration of Helsinki, and the protocol was approved by the University of Tennessee, Knoxville Institutional Review Board (UTK IRB-17-03670-XP).

\section{References}

1. U.S. Global Change Research Program. Fourth National Climate Assessment. 2018; pp. 1-470. Available online: https://nca2018.globalchange.gov/ (accessed on 25 November 2018).

2. Oke, T.R. The energetic basis of the urban heat island. Q. J. R. Meteorol. Soc. 1982, 108, 1-24. [CrossRef]

3. Ellis, K.N.; Hathaway, J.M.; Mason, L.R.; Howe, D.A.; Epps, T.H.; Brown, V.M. Summer temperature variability across four urban neighborhoods in Knoxville, Tennessee, USA. Theor. Appl. Climatol. 2017, 127, 701-710. [CrossRef]

4. Jenerette, G.D.; Harlan, S.L.; Buyantuev, A.; Stefanov, W.L.; Declet-Barreto, J.; Ruddell, B.L.; Myint, S.W.; Kaplan, S.; Li, X. Micro-scale urban surface temperatures are related to land-cover features and residential heat related health impacts in Phoenix, AZ USA. Landsc. Ecol. 2016, 31, 745-760. [CrossRef]

5. Hass, A.L.; Ellis, K.N.; Mason, L.R.; Hathaway, J.M.; Howe, D.A. Heat and humidity in the city: Neighborhood heat index variability in a mid-sized city in the Southeastern United States. Int. J. Environ. Res. Public Health 2016, 13, 117. [CrossRef] [PubMed]

6. Blum, L.N.; Bresolin, L.B.; Williams, M.A. Heat-Related Illness During Extreme Weather Emergencies. JAMA 1998, 279, 1514. [PubMed]

7. Sugg, M.M.; Fuhrmann, C.M.; Runkle, J.D. Temporal and spatial variation in personal ambient temperatures for outdoor working populations in the southeastern USA. Int. J. Biometeorol. 2018, 62, 1521-1534. [CrossRef] [PubMed]

8. Uejio, C.K.; Morano, L.H.; Jung, J.; Kintziger, K.; Jagger, M.; Chalmers, J.; Holmes, T. Occupational heat exposure among municipal workers. Int. Arch. Occup. Environ. Health 2018, 91, 705-715. [CrossRef] [PubMed]

9. National Weather Service (NWS). Weather Fatalities. 2007. Available online: http://www.nws.noaa.gov/om/ hazstats.shtml (accessed on 13 January 2019).

10. Semenza, J.C.; McCullough, J.E.; Flanders, W.D.; McGeehin, M.A.; Lumpkin, J.R. Excess hospital admissions during the July 1995 heat wave in Chicago. Am. J. Prev. Med. 1999, 16, 269-277. [CrossRef]

11. Centers for Disease Control and Prevention About Extreme Heat. Available online: https://www.cdc.gov/ disasters/extremeheat/heat_guide.html (accessed on 13 January 2019).

12. Hass, A.L.; Ellis, K.N. Using wearable sensors to assess how a heatwave affects individual heat exposure, perceptions, and adaption methods. Int. J. Biometeorol. 2019, 1-11. [CrossRef] [PubMed]

13. Sugg, M.M.; Konrad, C.E.; Fuhrmann, C.M. Relationships between maximum temperature and heat-related illness across North Carolina, USA. Int. J. Biometeorol. 2016, 60, 663-675. [CrossRef] [PubMed]

14. O'Neill, M.S.; Ebi, K.L. Temperature Extremes and Health: Impacts of Climate Variability and Change in the United States. J. Occup. Environ. Med. 2009, 51, 13-25. [CrossRef] [PubMed]

15. Mason, L.R.; Erwin, J.; Brown, A.; Ellis, K.N.; Hathaway, J.M. Health Impacts of Extreme Weather Events: Exploring Protective Factors with a Capitals Framework. J. Evid. Inf. Soc. Work 2018, 15, 579-593. [CrossRef] [PubMed]

16. Uejio, C.K.; Wilhelmi, O.V.; Golden, J.S.; Mills, D.M.; Gulino, S.P.; Samenow, J.P. Intra-urban societal vulnerability to extreme heat: The role of heat exposure and the built environment, socioeconomics, and neighborhood stability. Heal. Place 2011, 17, 498-507. [CrossRef] [PubMed]

17. Mason, L.R.; Ellis, K.N.; Hathaway, J.M. Experiences of Urban Environmental Conditions in Socially and Economically Diverse Neighborhoods. J. Community Pract. 2017, 25, 48-67. [CrossRef]

18. Kalkstein, A.J.; Sheridan, S.C. The social impacts of the heat-health watch/warning system in Phoenix, Arizona: Assessing the perceived risk and response of the public. Int. J. Biometeorol. 2007, 52, 43-55. [CrossRef] [PubMed]

19. Abrahamson, V.; Wolf, J.; Lorenzoni, I.; Fenn, B.; Kovats, S.; Wilkinson, P.; Adger, W.N.; Raine, R. Perceptions of heatwave risks to health: Interview-based study of older people in London and Norwich, UK. J. Public Health 2008, 31, 119-126. [CrossRef] [PubMed] 
20. Semenza, J.C.; Hall, D.E.; Wilson, D.J.; Bontempo, B.D.; Sailor, D.J.; George, L.A. Public Perception of Climate Change. Voluntary Mitigation and Barriers to Behavior Change. Am. J. Prev. Med. 2008, 35, 479-487. [CrossRef]

21. Sheridan, S.C. A survey of public perception and response to heat warnings across four North American cities: An evaluation of municipal effectiveness. Int. J. Biometeorol. 2007, 52, 3-15. [CrossRef]

22. Perry, R.W.; Lindell, M.K. Aged Citizens in the Warning Phase of Disasters: Re-Examining the Evidence. Int. J. Aging Hum. Dev. 1997, 44, 257-267. [CrossRef]

23. Bryman, A. Integrating quantitative and qualitative research: How is it done? Qual. Res. 2006, 6, 97-113. [CrossRef]

24. DeLyser, D.; Sui, D. Crossing the qualitative-quantitative chasm III. Prog. Hum. Geogr. 2014, 38, $294-307$. [CrossRef]

25. Elwood, S. Mixed Methods: Thinking, Doing, and Asking in Multiple Ways. In The SAGE Handbook of Qualitative Geography; DeLyser, D., Herbert, S., Aitken, S.C., Crang, M.A., McDowell, L., Eds.; Sage Publications Inc.: Los Angeles, CA, USA, 2009; pp. 94-113.

26. McGuirk, P.M.; O'Neill, P. Using Questionnaires in Qualitative Human Geography. In Qualitative Research Methods in Human Geography; Hay, I., Ed.; Oxford University Press: Don Mills, ON, Canada, 2010; pp. 191-216.

27. United States Census Bureau (USCB). U.S. Census Bureau QuickFacts: Knoxville city, Tennessee. Available online: https://www.census.gov/quickfacts/fact/table/knoxvillecitytennessee/POP060210 (accessed on 3 January 2018).

28. National Weather Service. Knoxville Climate Page. Available online: https://www.weather.gov/mrx/ tysclimate (accessed on 22 August 2019).

29. National Oceanic and Atmospheric Administration. Data Snapshots. Available online: https://www.climate. gov/maps-data/data-snapshots/averagemaxtemp-monthly-1981-2010-cmb-0000-07-00?theme=Temperature (accessed on 9 January 2019).

30. Robinson, P.J. On the Definition of a Heat Wave. J. Appl. Meteorol. 2000, 40, 762-775. [CrossRef]

31. National Weather Service (NWS). Watch, Warning, and Advisory Criteria For NWS Morristown TN. 2017. Available online: https://www.weather.gov/mrx/watchwarnadv (accessed on 8 May 2017).

32. United States Census Bureau (USCB). American Fact Finder. Available online: http://factfinder.census.gov/ faces/tableservices/jsf/pages/productview.xhtml?src=bkmk (accessed on 16 September 2015).

33. United States Census Bureau. Quick Facts, Knoxville city, Tennessee. Available online: https://www.census. gov/quickfacts/knoxvillecitytennessee (accessed on 9 January 2019).

34. Curtin, R.; Presser, S.; Singer, E. The Effects of Response Rate Changes on the Index of Consumer Sentiment. Public Opin. Q. 2000, 64, 413-428. [CrossRef] [PubMed]

35. Singer, E.; Van Hoewyk, J.; Maher, M.P. Experiments with Incentives in Telephone Surveys. Public Opin. Q. 2000, 64, 171-188. [CrossRef]

36. Miles, M.B.; Huberman, A.M.; Saldana, J. Qualitative Data Analysis: A Methods Sourcebook, 3rd ed.; Sage Publications, Inc.: Los Angeles, CA, USA, 2014; ISBN 9781452257877.

37. Yates, F. Contingency Tables Involving Small Numbers And The X2 Test. Suppl. J. R. Stat. Soc. 1934, 1, 217-235. [CrossRef]

38. Arcury, T.A.; Quandt, S.A. Participant Recruitment for Qualitative Research: A Site-Based Approach to Community Research in Complex Societies. Source Hum. Organ. 1999, 58, 128-133. [CrossRef]

39. Campbell, L.M.; Gray, N.J.; Meletis, Z.A.; Abbott, J.G.; Silver, J.J. Gatekeepers and Keymasters: Dynamic Relationships of Access in Geographical Fieldwork. Geogr. Rev. 2010, 96, 97-121. [CrossRef]

40. Tongco, M.D.C. Purposive Sampling as a Tool for Informant Selection. Ethnobot. Res. Appl. 2007, 5, 147-158. [CrossRef]

41. World Health Organization. How to Investigate the Use of Medicines by Consumers: 5. Sampling: 5.5 Bias in Sampling. Available online: http://apps.who.int/medicinedocs/en/d/Js6169e/7.5.html (accessed on 20 January 2019).

42. National Weather Service. Excessive Heat Conditions. Available online: https://www.weather.gov/phi/ heatcond (accessed on 21 January 2019).

43. Heusinkveld, B.G.; SterenBorG, G.; Steeneveld, G.J.; AttemA, J.J.; RondA, J.; HoltslAG, A.A. Smartphone App Brings Human Thermal Comfort Forecast in Your Hands. Bull. Am. Meteorol. Soc. 2017, 98, 2533-2541. [CrossRef] 
44. Sandman, P.M. Mass Media and Environmental Risk: Seven Principles. Risk Heal. Saf. Environ. 1994, 5, 251-260.

45. Browning, C.R.; Wallace, D.; Feinberg, S.L.; Cagney, K.A. Neighborhood Social Processes, Physical Conditions, and Disaster-Related Mortality: The Case of the 1995 Chicago Heat Wave. Am. Sociol. Rev. 2006, 71, 661-678. [CrossRef]

46. Hosokawa, Y.; Casa, D.J.; Trtanj, J.M.; Belval, L.N.; Deuster, P.A.; Giltz, S.M.; Grundstein, A.J.; Hawkins, M.D.; Huggins, R.A.; Jacklitsch, B.; et al. Activity modification in heat: Critical assessment of guidelines across athletic, occupational, and military settings in the USA. Int. J. Biometeorol. 2019, 63, 405-427. [CrossRef] [PubMed]

47. Toloo, G.S.; Fitzgerald, G.; Aitken, P.; Verrall, K.; Tong, S. Are heat warning systems effective? Environ. Health 2013, 12, 27. [CrossRef] [PubMed]

(C) 2019 by the authors. Licensee MDPI, Basel, Switzerland. This article is an open access article distributed under the terms and conditions of the Creative Commons Attribution (CC BY) license (http://creativecommons.org/licenses/by/4.0/). 